\title{
Aminoguanidine affects systemic and lung inflammation induced by lipopolysaccharide in rats
}

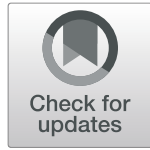

\author{
Saeideh Saadat ${ }^{1,2}$, Farimah Beheshti ${ }^{3,4}$, Vahid Reza Askari ${ }^{1,5}$, Mahmoud Hosseini ${ }^{1,2}$, \\ Nema Mohamadian Roshan ${ }^{6}$ and Mohammad Hossein Boskabady ${ }^{1,2^{*}}$
}

\begin{abstract}
Background: Nitric oxide is a mediator of potential importance in numerous physiological and inflammatory processes in the lung. Aminoguanidine (AG) has been shown to have anti-inflammation and radical scavenging properties. This study aimed to investigate the effects of AG, an iNOS inhibitor, on lipopolysaccharide (LPS)-induced systemic and lung inflammation in rats.

Methods: Male Wistar rats were divided into control, LPS (1 mg/kg/day i.p.), and LPS groups treated with AG 50, 100 or $150 \mathrm{mg} / \mathrm{kg} /$ day i.p. for five weeks. Total nitrite concentration, total and differential white blood cells (WBC) count, oxidative stress markers, and the levels of IL-4, IFN- $\gamma$, TGF- $\beta 1$, and PGE2 were assessed in the serum or bronchoalveolar lavage fluid (BALF).

Results: Administration of LPS decreased IL-4 level $(p<0.01)$ in BALF, total thiol content, superoxide dismutase (SOD) and catalase (CAT) activities $(p<0.001)$ in BALF and serum, and increased total nitrite, malondialdehyde (MDA), IFN- $\gamma$, TGF- $\beta 1$ and PGE2 $(p<0.001)$ concentrations in BALF. Pre-treatment with AG increased BALF level of IL-4 and total thiol as well as SOD and CAT activities ( $p<0.05$ to $p<0.001$ ), but decreased BALF levels of total nitrite, MDA, IFN- $\gamma$, TGF- $\beta 1$, and PGE2 $(p<0.01$ to $p<0.001)$. AG treatment decreased total WBC count, lymphocytes and macrophages in BALF $(p<0.01$ to $p<0.001)$ and improved lung pathological changes including interstitial inflammation and lymphoid infiltration $(p<0.05$ to $p<0.001)$.

Conclusions: AG treatment reduced oxidant markers, inflammatory cytokines and lung pathological changes but increased antioxidants and anti-inflammatory cytokines. Therefore, AG may play a significant protective role against inflammation and oxidative stress that cause lung injury.
\end{abstract}

Keywords: Aminoguanidine, Inflammation, Lipopolysaccharide, Lung injury, Nitric oxide

\section{Background}

Bacterial lipopolysaccharide (LPS), also termed endotoxin, has shown pro-inflammatory activities [1]. LPS is present as a contaminant in cigarette-smoke, air pollution and organic dusts [2]. Average ambient air LPS concentration was measured at $\pm 0.4 \mathrm{ng} / \mathrm{m}^{3}$ [3]. LPS inhalation stimulates the innate immune system in healthy human subjects and results in an acute

\footnotetext{
*Correspondence: boskabadymh@mums.ac.ir; boskabadymh2@gmail.com ${ }^{1}$ Neurogenic Inflammation Research Center, Mashhad University of Medical Sciences, Mashhad 9177948564, Iran

${ }^{2}$ Department of Physiology, School of Medicine, Mashhad University of Medical Sciences, Mashhad 9177948564, Iran

Full list of author information is available at the end of the article
}

lung and systemic inflammation. [3]. The consequences of these inflammatory responses include overproduction of nitric oxide (NO), tissue injury and organ failure [4]. It has been demonstrated that LPS leads to lung injury [5-8]. Chronic exposure of animals to LPS has been also shown to induce pathological features of COPD, such as pulmonary inflammation and airway hyperresponsiveness as well as structural changes in the lung [3, 9-12]. Follow-up studies have shown that long-term LPS exposure resulted in pulmonary function decline and a major lung inflammatory response. However, the extent of

(c) The Author(s). 2019 Open Access This article is distributed under the terms of the Creative Commons Attribution 4.0 International License (http://creativecommons.org/licenses/by/4.0/), which permits unrestricted use, distribution, and 
inflammatory processes in lung pathology of these patients is still unclear [3].

$\mathrm{NO}$, a potentially toxic free radical and physiological messenger, has a major role in the regulation of the immune system functions [13] including aggregation of platelets, rolling and migration of leukocytes, and expression of inflammatory cytokines such as interleukin-1 (IL-1), interleukin-6 (IL-6), interleukin-8 (IL-8), interferon gamma (INF- $\gamma$ ) and tumor necrosis factor-alpha (TNF- $\alpha$ ) [14]. During the inflammation process, endotoxins and cytokines induced rapid alterations in NO gene expression leading to the de novo synthesis of the inducible isoform of nitric oxide synthases (iNOS) and cyclooxygenase (COX-2) pathways. There are interrelated and the cross-talk between these two pathways which play a key role in the regulation of the inflammatory processes [13].

In several animal models of lung injury, inflammation and oxidative stress are involved as the underlying pathophysiological mechanisms. Thus, anti-inflammatory or antioxidant agents have been widely used to alleviate lung injury [6]. Aminoguanidine (AG), an iNOS inhibitor, affects several enzyme systems [15]. Inhibition of NO, arachidonic acid metabolites and cytokines production can be advantageous in the systemic and lung inflammation. AG was prepared more than 100 years ago [16], but relatively less attention has been paid to its beneficial effects on the respiratory system. It has been suggested that enhanced generation of NO by iNOS may contribute to acute lung injury [17]. Therefore, the present study set up to evaluate the role of inhibition of NO production by administration of AG on LPS-induced chronic systemic inflammation and oxidative stress in a rat lung injury model.

\section{Methods}

\section{Animals}

Fifty male Wistar rats $(240 \pm 10 \mathrm{~g})$ were purchased from the Animal House, Mashhad University of Medical Sciences and were housed in Plexiglas cages under controlled temperature $\left(22 \pm 2{ }^{\circ} \mathrm{C}\right)$, humidity $(54 \pm 2 \%)$, and $12 \mathrm{~h} \mathrm{light/dark}$ cycle. Food and water were freely available during the study period. The study was approved by the ethics committee of Mashhad University of Medical Sciences for Animal Experiments (code 951071).

\section{Experimental groups}

Rats were randomly divided into five groups $(n=10$ in each group) as follows: (1) Control group received saline instead of LPS and AG, (2) LPS group received LPS $1 \mathrm{mg} / \mathrm{kg} /$ day [18] for 5 weeks, (3-5) LPS groups treated with 50,100 or $150 \mathrm{mg} / \mathrm{kg} /$ day AG $30 \mathrm{~min}$ before LPS injection, during 5 weeks. LPS and AG (Sigma-Aldrich Chemical Co) freshly dissolved in sterile warm saline before injection and administrated intra-peritoneally (i.p.).

At the end of the experiment, all animals were anesthetized by urethane $(1.6 \mathrm{~g} / \mathrm{kg})$. To prepare blood serum, $5 \mathrm{ml}$ blood was collected from the animal's heart after opening the chest in the test tube and centrifuged at $3500 \mathrm{rpm}$ for $10 \mathrm{~min}$. The serum samples were collected and stored at $-70^{\circ} \mathrm{C}$ for measurement of the levels of nitrite, malondialdehyde (MDA), total thiol content, superoxide dismutase (SOD) and catalase (CAT) activity [18].

\section{Bronchoalveolar lavage fluid (BALF) preparation}

The chest was opened and the left lung was clamped to preserve architecture for histological studies. A cannula was placed into the trachea and the right lung was washed with one $\mathrm{mL}$ normal saline for five times (totally, $5 \mathrm{ml}$ ) through a tracheal cannula according to previous studies [18]. BALF was centrifuged at $2500 \mathrm{rpm}$ at $4{ }^{\circ} \mathrm{C}$ for $10 \mathrm{~min}$. The supernatant was collected and stored at $-70^{\circ} \mathrm{C}$ for measurement of the levels of nitrite and cytokines, and assessment of oxidative stress.

\section{Measurement of total nitrite concentration}

Total nitrite concentration was measured in the serum and BALF by Griess reagent method using a standard enzyme-linked immunosorbent assay (ELISA) kit (Promega Corp., USA, Cat\#G2930). In brief, $100 \mu$ of serum or BALF were added to a 96-well flat-bottomed microplate. Then, sulfanilamide solution and N-1-naphtylethylenediamine dihydrochloride under acidic conditions were added to all collected samples, respectively. The absorbance was detected by a microplate reader (Biotek, USA) at $520-550 \mathrm{~nm}$ wavelengths. The limit detection was $2.5 \mu \mathrm{M}$ nitrite [19].

\section{Total and differential white blood cell (WBC) counts}

Total leukocyte was determined in duplicate using a hemocytometer (in a Burker chamber). For differential WBC count, a smear was prepared from the cell pellet in BALF and blood sample and stained with Wright-Giemsa. After staining, differential count was carried out by standard morphologic protocol under the light microscope.

\section{Assessment of oxidative stress markers}

MDA, a biological marker of lipid peroxidation, was assayed in the serum and BALF based on the reaction between MDA and thiobarbituric acid (TBA) as described previously [20]. Total thiol content was also assayed in the serum and BALF using a previous established method [20]. Here, 5, 5'-dithiobis-(2-nitrobenzoic 
acid) (DTNB) interact with SH groups, forming a highly colored anion with the maximum peak at $412 \mathrm{~nm}$. MDA and Total thiol contents were expressed as $\mu \mathrm{M}$.

SOD activity was assayed in the serum and BALF according to the previously described method [20]. The method is based on the generation of superoxide through auto-oxidation of pyrogallol and dependent revived inhibition of 3-(4,5-dimethyl-thiazol-2-yl) 2,5-diphenyl tetrazolium bromide (MTT) to formazan [20]. CAT activity was assayed based on its ability to decompose hydrogen peroxide $\left(\mathrm{H}_{2} \mathrm{O}_{2}\right)$, which is reflected in the reduction of absorption at $240 \mathrm{~nm}$ [20]. SOD and CAT activities were expressed as units per $\mathrm{ml}$.

\section{Measurement of IL-4, IFN- $\gamma$, TGF- $\beta 1$, and PGE2 in BALF}

Specific ELISA kits (ebioscience Co, San Diego, CA, USA) and the instructions provided by the manufacturer were used to measure interleukin-4 (IL-4), interferon-gamma (IFN- $\gamma$ ), transforming growth factor-beta-1 (TGF- $\beta 1$ ), and prostaglandin-E2 (PGE2) in BALF. The measured absorbance of the samples in a microplate reader (Biotek, USA) was compared with an established standard curve in the same measurement, and the cytokines concentrations were calculated.

\section{Lung histopathological evaluation}

Histological examination was performed on left lung which was not lavaged. The left lung was fixed in $10 \%$ buffered formalin (37\%, Merck, Germany) and embedded in paraffin blocks. The specimens were cut into $4 \mu \mathrm{m}$ slices and were stained with hematoxylin-eosin (H\&E) solution. The tissues were then evaluated under a light microscope. The pathologic changes in the lung of different groups were included: interstitial inflammation and lymphoid infiltration. The scoring system of pathological changes was: 0 , no pathologic changes; 1 , patchy changes; 2 , local changes; 3 , scattered changes; 4 , severe changes (in the most parts of the lung) [21].

\section{Statistical analysis}

All results were considered as mean \pm SEM. The percent change in all measured parameters in the LPS compared to control and in LPS-AG treated compared to untreated LPS groups were also calculated.
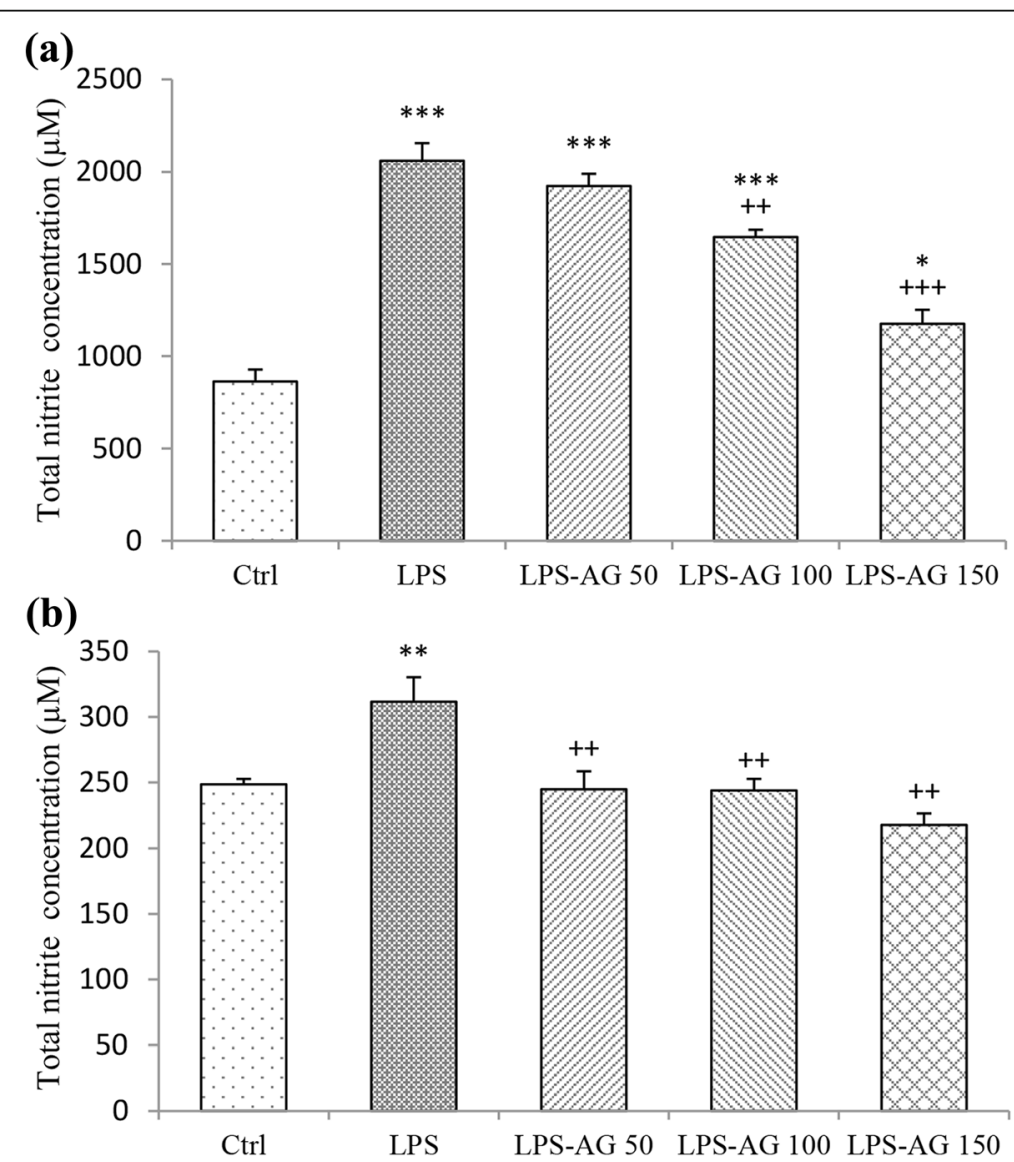

Fig. 1 Total nitrite concentration in the serum (a) and BALF (b). Data are shown as mean \pm SEM ( $n=10$ per group). $*_{;}^{*} P<0.05,{ }^{* *} ; P<0.01$ and ***;P $P 0.001$ compared to control group, $++; P<0.01$ and $+++; P<0.001$ compared to LPS group. Statistical analysis were performed using oneway analysis of variance (ANOVA) followed by Tukey's multiple comparison test 
The data were analyzed using one-way analysis of variance (ANOVA) followed by Tukey's multiple comparison test. Statistically significant was considered as $p<0.05$.

\section{Results}

\section{Total nitrite concentration}

The serum and BALF nitrite levels of LPS groups were increased by $238 \%(2060.91 \pm 93.23)$ and $125 \%$ (311.63 \pm $18.72)$, respectively relative to control group $(864.7 \pm$ 62.89 and $248.46 \pm 4.24$, for serum and BALF), $(P<0.001$ and $P<0.01$, respectively), (Table and Fig. 1). In AG treated groups with doses of 100 and $150 \mathrm{mg} / \mathrm{kg}$, serum nitrite concentrations were reduced to $79 \%(1646.70 \pm 39.41)$ and 57\% (1175.90 \pm 75.69$)$, respectively relative to LPS group (2060.91 \pm 93.23$), \quad(P<0.01$ and $P<0.001$, respectively), (Table 1 and Fig. 1a). Additionally, pre-treatment

Table 1 Percent changes of various measured parameters in LPS relative to control and in AG treated relative to LPS groups (\%)

\begin{tabular}{|c|c|c|c|c|c|}
\hline \multirow[t]{2}{*}{ Parameters } & \multirow[t]{2}{*}{ Sample } & \multirow{2}{*}{$\begin{array}{l}\text { LPS/ } \\
\text { Ctrl }\end{array}$} & \multicolumn{3}{|c|}{ AG/LPS } \\
\hline & & & 50 & 100 & 150 \\
\hline \multirow[t]{2}{*}{ Total nitrite concentration } & Serum & 238 & 93 & 79 & 57 \\
\hline & BALF & 125 & 78 & 78 & 69 \\
\hline \multirow[t]{2}{*}{ Total WBC count } & Blood & 141 & 91 & 85 & 77 \\
\hline & BALF & 182 & 97 & 86 & 73 \\
\hline \multirow[t]{2}{*}{ Neutrophils } & Blood & 138 & 87 & 83 & 80 \\
\hline & BALF & 126 & 100 & 92 & 95 \\
\hline \multirow[t]{2}{*}{ Lymphocytes } & Blood & 142 & 93 & 86 & 75 \\
\hline & BALF & 175 & 97 & 88 & 74 \\
\hline Monocytes & Blood & 155 & 88 & 82 & 73 \\
\hline Macrophages & BALF & 320 & 96 & 78 & 56 \\
\hline \multirow[t]{2}{*}{ Eosinophils } & Blood & 109 & 108 & 100 & 91 \\
\hline & BALF & 150 & 85 & 100 & 83 \\
\hline \multirow[t]{2}{*}{ MDA concentration } & Serum & 240 & 86 & 62 & 53 \\
\hline & BALF & 623 & 71 & 68 & 44 \\
\hline \multirow[t]{2}{*}{ Total thiol content } & Serum & 26 & 106 & 162 & 232 \\
\hline & BALF & 16 & 86 & 124 & 368 \\
\hline \multirow[t]{2}{*}{ SOD activity } & Serum & 10 & 292 & 370 & 585 \\
\hline & BALF & 13 & 295 & 468 & 528 \\
\hline \multirow[t]{2}{*}{ CAT activity } & Serum & 33 & 133 & 165 & 214 \\
\hline & BALF & 8 & 263 & 398 & 583 \\
\hline $\mid \mathrm{L}-4$ & BALF & 42 & 101 & 155 & 222 \\
\hline IFN- $\gamma$ & BALF & 293 & 82 & 70 & 45 \\
\hline TGF- $\beta 1$ & BALF & 281 & 86 & 73 & 46 \\
\hline PGE2 & BALF & 301 & 79 & 68 & 42 \\
\hline Interstitial inflammation & Lung tissue & 732 & 100 & 90 & 63 \\
\hline Lymphoid infiltration & Lung tissue & 666 & 79 & 75 & 49 \\
\hline
\end{tabular}

with all doses of AG decreased BALF total nitrite concentration to $78 \%(244.83 \pm 13.71), 78 \%(243.92 \pm 8.82)$ and $69 \%(217.93 \pm 8.42)$, respectively relative to LPS group (311.63 \pm 18.72 ), (all, $P<0.01$ ), (Table 1 and Fig. $1 b$ ).

\section{Total and differential WBC counts}

The results showed that total WBC count in the blood was increased by $141 \%(13.99 \pm 0.50)$ in LPS group relative to control group $(9.895 \pm 0.40),(p<0.001)$ which was due to the increased numbers of neutrophils, lymphocytes and monocytes by $138 \%(4.08 \pm 0.40), 142 \%$ $(9.4 \pm 0.50)$ and $155 \%(0.45 \pm 0.03)$, respectively relative to control groups $(2.95 \pm 0.20,6.6 \pm 0.70$ and $0.29 \pm 0.01$, for neutrophils, lymphocytes and monocytes respectively), ( $p<0.05$ to $p<0.001$, Table 1 , Fig. 2 ).

In the treated groups with three doses of AG, total WBC counts were reduced to $91 \%(12.845 \pm 1.00), 85 \%$ $(11.98 \pm 0.70)$ and $77 \%(10.785 \pm 0.40)$ relative to LPS group $(13.99 \pm 0.50)$, (Table 1$)$ which were significant at doses of 100 and $150 \mathrm{mg} / \mathrm{kg}(\mathrm{p}<0.05$ and $p<0.01$, respectively; Fig. 2a). In AG treated groups with three doses of AG, neutrophils count was reduced to $87 \%$ (3.58 \pm 0.50$), 83 \%(3.4 \pm 0.55)$ and $80 \%(3.3 \pm 0.60)$, lymphocytes count was reduced to $93 \%(8.8 \pm 1.00), 86 \%$ $(8.15 \pm 1.60)$ and $75 \%(7.1 \pm 0.50)$, monocytes count was reduced to $88 \%(0.4 \pm 0.05), 82 \%(0.37 \pm 0.06)$ and $73 \%$ $(0.33 \pm 0.03)$, and eosinophils count was reduced to $91 \%$ $(0.05 \pm 0.01)$, only by $150 \mathrm{mg} / \mathrm{kg}$ dose of AG relative to LPS groups (4.08 $\pm 0.40,9.40 \pm 0.50,0.45 \pm 0.03$ and 0.06 \pm 0.01 , for neutrophils, lymphocytes, monocytes and eosinophils respectively), (Table 1 ) which were statistically significant at dose of $150 \mathrm{mg} / \mathrm{kg}$ for mononuclear leukocytes $(p<0.05$ for lymphocyte cells and $p<0.01$ for monocyte cells; Fig. 2b-d).

Total WBC count in BALF was increased by $182 \%$ $(6.36 \pm 0.50)$ in LPS group relative to control group $(3.49 \pm 0.40),(p<0.001)$ which was due to the increased lymphocytes and macrophages counts in BALF of LPS groups by increased 175\% (3.50 \pm 0.30$)$ and 320\% (1.60 \pm $0.10)$, respectively relative to control groups $(2.00 \pm 0.20$ and $0.50 \pm 0.05$, for lymphocytes and macrophages), (all, $p<0.001$ ).

In the treated groups with three doses of AG, total WBC counts in BALF were reduced to $97 \%(6.21 \pm 1.00)$, $86 \%(5.52 \pm 0.70)$ and $73 \%(4.70 \pm 0.40)$, respectively relative to LPS group $(6.36 \pm 0.50)$, (Table 1$)$ which was significant at AG $150 \mathrm{mg} / \mathrm{kg}(p<0.01$; Fig. 3).

In AG treated groups, lymphocytes count was reduced to $97 \%(3.40 \pm 0.30), 88 \%(3.10 \pm 0.30)$ and $74 \%(2.60 \pm$ $0.20)$, and macrophages count was reduced to $96 \%$ (1.55 $\pm 0.10), 78 \%(1.25 \pm 0.20)$ and $56 \%(0.90 \pm 0.09)$, due to its three doses respectively, relative to LPS group (1.60 \pm 0.10 ), (Table 1) which were significant for AG $150 \mathrm{mg} / \mathrm{kg}$ (both, $p<0.01$; Fig. 3). 

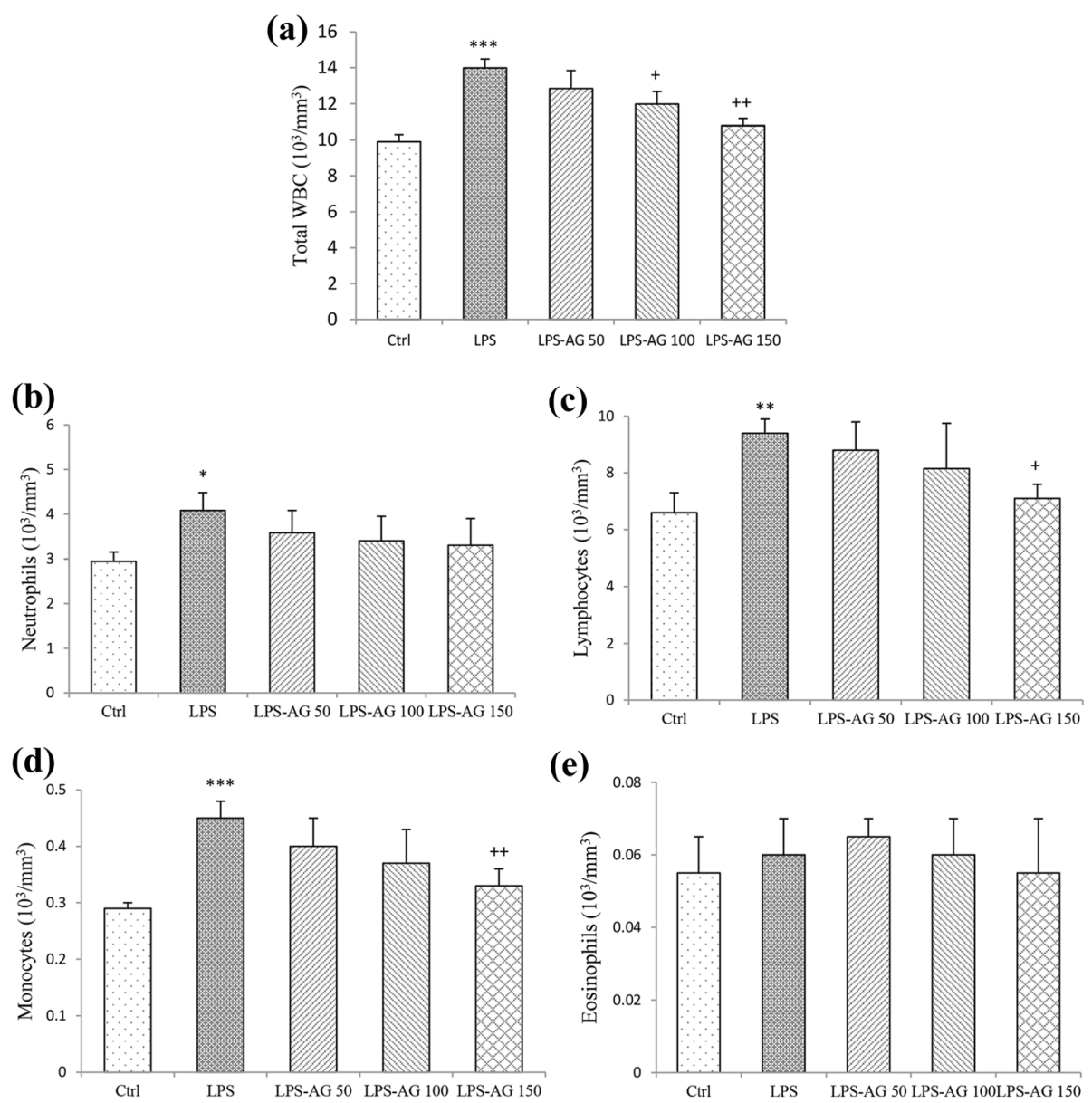

Fig. 2 Total and differential WBC counts in the blood. Data are shown as mean \pm SEM ( $n=10$ per group). ${ }^{*} P<0.05,{ }^{* *} ; P<0.01$ and ${ }^{* * *} ; P<0.001$ compared to control group, $+; P<0.05$ and $++; P<0.01$ compared to LPS group. Statistical analysis were performed using one-way analysis of variance (ANOVA) followed by Tukey's multiple comparison test

\section{Oxidant marker (MDA) content}

Serum and BALF MDA concentrations of LPS group were increased by $240 \%(1.26 \pm 0.14)$ and $623 \%(1.55 \pm$ $0.11)$, respectively relative to control groups $(0.52 \pm 0.06$ and $0.25 \pm 0.07$, for Serum and BALF), (both, $p<0.001$ ). In AG treated groups, serum MDA concentrations were reduced to $62 \%(0.79 \pm 0.10)$ and $53 \%(0.67 \pm 0.03)$ relative to LPS group $(1.26 \pm 0.14),(p<0.01$ for AG 100 and $150 \mathrm{mg} / \mathrm{kg}$ ). BALF MDA concentration was reduced to $71 \%(1.10 \pm 0.06), 68 \%(1.06 \pm 0.11)$ and $44 \%$ $(0.69 \pm 0.09)$, respectively by three doses of AG relative to LPS group (1.55 \pm 0.11$),(\mathrm{p}<0.01$ to $p<0.001)$, (Figs. $4 \mathrm{a}$ and $5 \mathrm{a}$, and Table 1).

\section{Anti-oxidant markers (thiol, SOD and CAT)}

In LPS group, total thiol content, SOD and CAT activities in the serum were reduced to $26 \%(0.09 \pm 0.01)$, $10 \%(0.28 \pm 0.08)$ and $33 \%(0.01 \pm 0.00)$, respectively, relative to control group $(0.36 \pm 0.02,2.80 \pm 0.18$ and $0.04 \pm 0.00$, for total thiol content, SOD and CAT respectively), (all, $p<0.001$ ). Additionally, total thiol content, SOD and CAT activities in BALF were reduced to $16 \%(0.07 \pm 0.00), 13 \%(0.32 \pm 0.10)$ and $8 \%(0.01 \pm$ $0.00)$, respectively, relative to control groups $(0.48 \pm$ $0.03,2.38 \pm 0.13$ and $0.14 \pm 0.00$, for total thiol content, SOD and CAT respectively), (all, $p<0.001$ ), (Fig. 5b-d and Table 1).

In the serum of AG $150 \mathrm{mg} / \mathrm{kg}$ treated group, total thiol content was increased by $232 \%(0.22 \pm 0.02)$, and SOD activity was increased by $585 \%(1.67 \pm 0.41)$, (both, $p<0.01)$. Pre-treatment with AG 100 and $150 \mathrm{mg} / \mathrm{kg}$ increased CAT activity to $165 \%(0.02 \pm 0.00)$ and $214 \%$ $(0.03 \pm 0.00), \quad(p<0.01$ and $p<0.001, \quad$ respectively $)$, (Fig. 4b-d and Table 1). In BALF of AG treated groups, SOD activity was increased by $295 \%(0.96 \pm$ $0.10), 468 \%(1.53 \pm 0.12)$ and $528 \%(1.72 \pm 0.09)$, and CAT activity was increased by $263 \% \quad(0.03 \pm 0.00)$, $398 \%(0.05 \pm 0.00)$ and $583 \%(0.07 \pm 0.00),(p<0.01$ to $p<0.001)$, relative to LPS groups $(0.32 \pm 0.10$ and $0.01 \pm 0.00$, for SOD and CAT). Pre-treatment with 

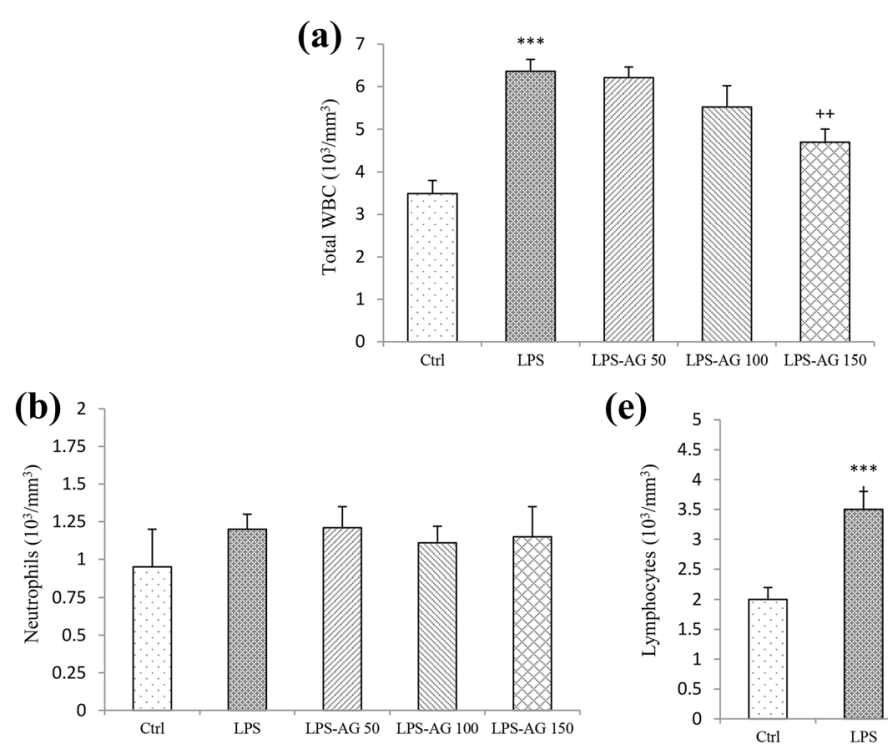

(e)
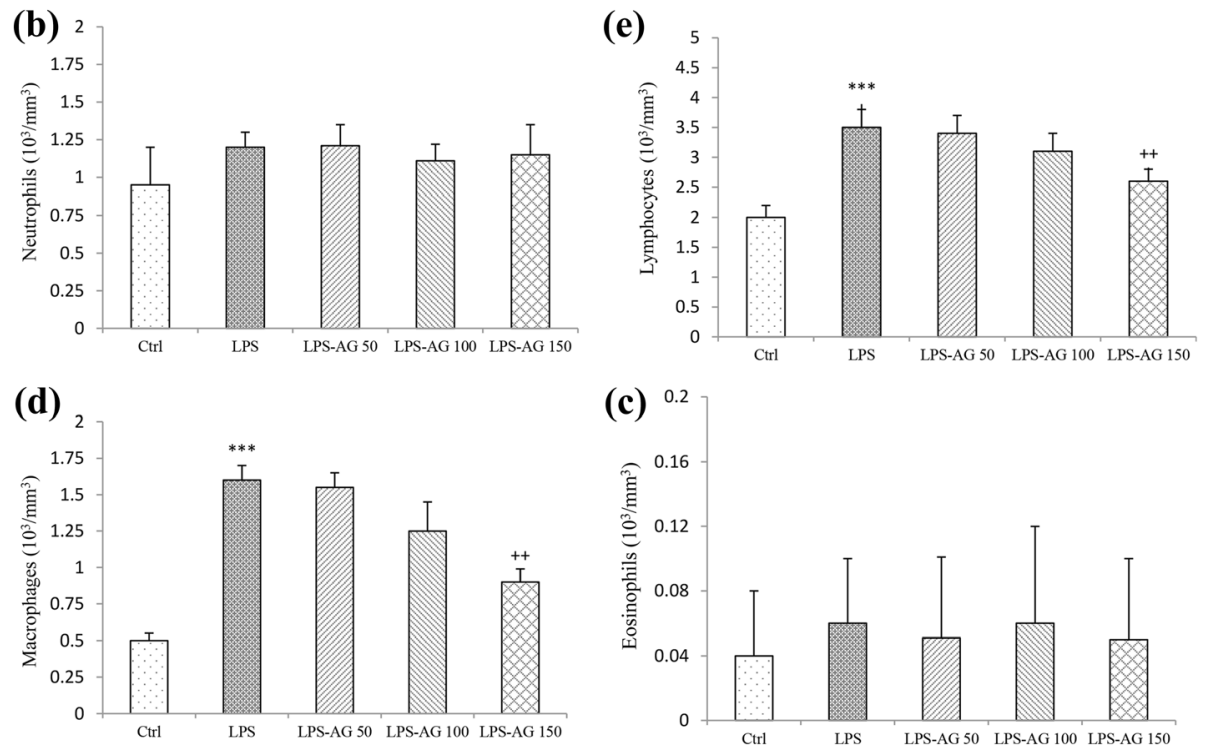

Fig. 3 Total and differential WBC counts in BALF. Data are shown as mean \pm SEM ( $n=10$ per group). ***P $<0.001$ compared to control group, $++; P<0.01$ compared to LPS group. Statistical analysis were performed using one-way analysis of variance (ANOVA) followed by Tukey's multiple comparison test. The reason of unchanged neutrophil count in BALF of LPS group is unknown to us

AG $150 \mathrm{mg} / \mathrm{kg}$ increased total thiol content by $368 \%(0.28$ $\pm 0.01)$, relative to LPS group $(0.07 \pm 0.00),(p<0.001)$, (Fig. 5b-d and Table 1).

\section{Levels of IL-4, IFN- $\gamma$, TGF- $\beta 1$, and PGE2 in BALF}

In LPS group, BALF level of IL-4 was reduced to $42 \%$ $(14.69 \pm 1.93), \quad(p<0.01)$, and the levels of IFN- $\gamma$, TGF- $\beta 1$ and PGE2 were increased to $293 \%$ (115.15 \pm $13.51), 281 \%(189 \pm 22.17)$ and $301 \%(26.52 \pm 3.11)$, respectively, relative to control groups $(34.55 \pm 3.57$, $39.25 \pm 5.31,64.42 \pm 8.71$ and $9.04 \pm 1.22$, for IL-4, IFN- $\gamma$, TGF- $\beta 1$ and PGE2 respectively) (all, $p<0.001$ ), (Fig. 6a-d and Table 1). In AG $150 \mathrm{mg} / \mathrm{kg}$ treated group, IL-4 level was increased to $222 \%(32.75 \pm 3.00)$, $(\mathrm{p}<0.001)$, while IFN- $\gamma$ level reduced to $45 \%(52.06 \pm$ 6.43), TGF- $\beta 1$ level was reduced to $46 \%(85.45 \pm 10.55)$, and PGE2 level was reduced to $42 \%(11.99 \pm 1.48)$, relative to LPS groups $(14.69 \pm 1.93,115.15 \pm 13.51$, $189 \pm 22.17$ and $26.52 \pm 3.11$, for IL-4, IFN- $\gamma$, TGF- $\beta 1$ and PGE2 respectively), (all, $p<0.01$ ), (Fig. 6a-d and Table 1).

\section{Lung histopathological evaluation}

Pathological changes in the LPS group, including the interstitial inflammation and lymphoid infiltration were increased to $732 \%(3.66 \pm 0.21)$ and $666 \%(3.33 \pm 0.21)$, respectively relative to control group $(0.5 \pm 0.22$ for the interstitial inflammation and lymphoid infiltration), ( $p<0.001$ for both cases; Fig. 7 and Table 1).

In the treated groups, interstitial inflammation was reduced to $63 \%(2.33 \pm 0.21)$ and lymphoid infiltration was reduced to $79 \%(2.66 \pm 0.21), 75 \%(2.5 \pm 0.22)$ and $49 \%$ $(1.66 \pm 0.21)$, respectively, relative to LPS group (3.66 \pm 0.21 and $3.33 \pm 0.21$, for the interstitial inflammation and lymphoid infiltration), (Table 1) which were statistically significant at doses of 50 and $100 \mathrm{mg} / \mathrm{kg}$ for lymphocyte infiltration $(p<0.05)$ and $150 \mathrm{mg} / \mathrm{kg}$ for interstitial inflammation and lymphoid infiltration $(p<0.01$ and $p<0.001$, respectively).

\section{Discussion}

The results of the present study showed that chronic i.p. administration of LPS for five weeks has led to an increase in total nitrite concentration, and WBC 

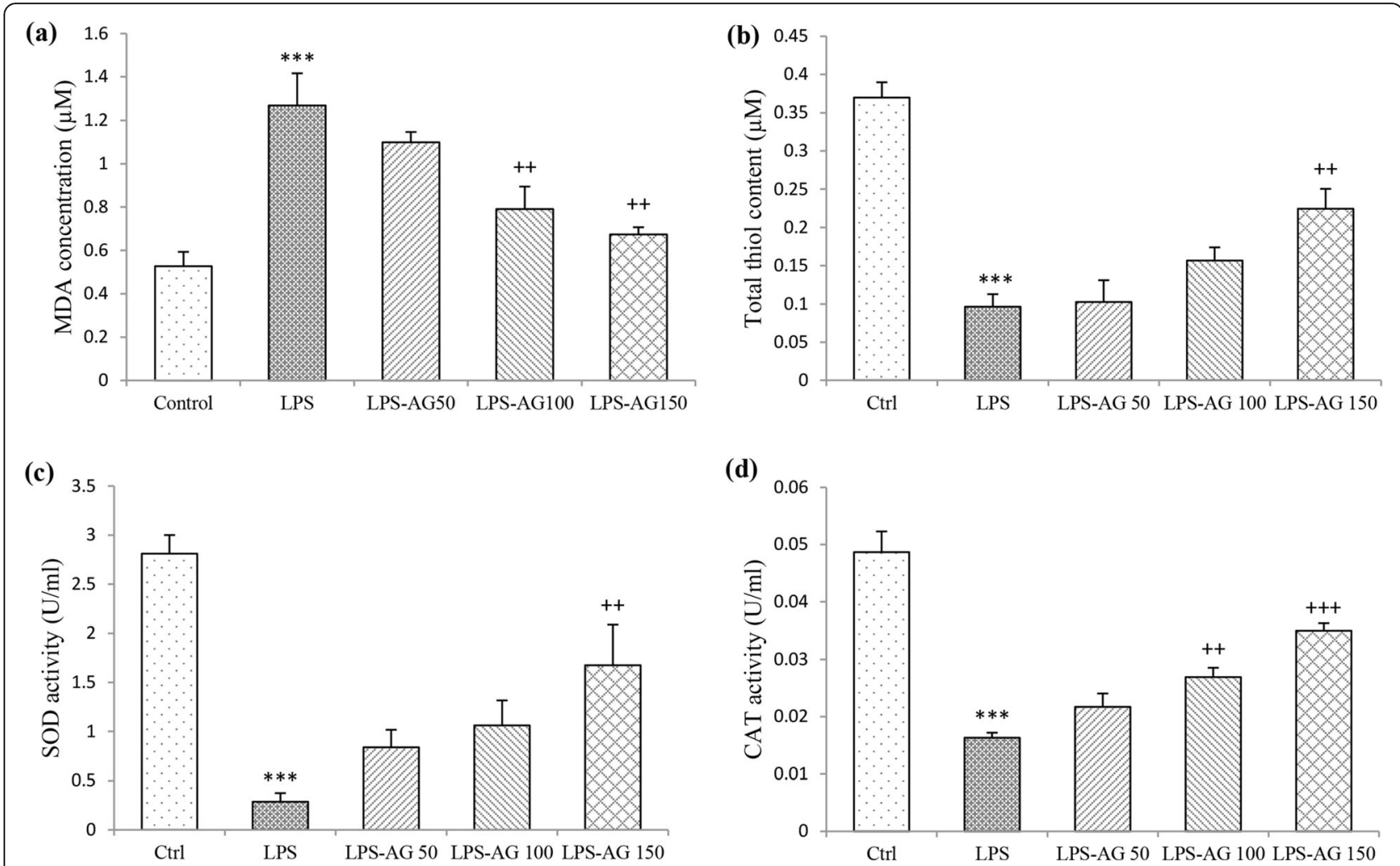

Fig. 4 MDA concentration (a), thiol content (b), SOD (c) and CAT activities (d) in the serum. Data are shown as mean \pm SEM ( $n=10$ per group). ***; $P<0.001$ compared to control group, $++; P<0.01$ and +++; $P<0.001$ compared to LPS group. Statistical analysis were performed using oneway analysis of variance (ANOVA) followed by Tukey's multiple comparison test

count as well as elevated monocytes, lymphocytes and neutrophils counts in the blood and lung lavage. LPS also induced oxidative damage by increasing MDA concentration and decreasing total thiol concentration as well as SOD and CAT activities in the serum and lavage. Decreased IL-4 level and increased IFN- $\gamma$, TGF- $\beta 1$, PGE2 levels in the lung lavage were also observed due to chronic LPS administration. At five weeks after LPS administration, severe pathological changes including interstitial inflammation and lymphoid infiltration were also observed.

Previous studies showed that long-term LPS exposure induced various types of pulmonary diseases which characterized by chronic inflammatory processes in the lung [3]. In acute lung injury, a major component of the inflammatory response is infiltration of activated neutrophils into the lung [22]. Animal experiments have demonstrated bronchoalveolar neutrophilia being the most prominent cell response following bacterial LPS inhalation [23]. LPS inhalation in healthy subjects increased neutrophils and lymphocytes levels in BALF [23]. Acute LPS exposure increased neutrophil count in BALF in both rabbits [24] and rats [25]. Increased neutrophils count in BALF of mice was detected $1 \mathrm{~h}$ post
LPS inhalation which was persisted for $48 \mathrm{~h}$ [26]. In the present chronic lung injury model of LPS exposure, there was no significant increase in neutrophil count in BALF. However, the results indicated increased total WBC in the blood by $141 \%$ which was due to increased monocytes, lymphocytes and neutrophils counts but in the lavage by $182 \%$ which was accompanied by increased macrophage and lymphocytes. The reason of unchanged neutrophil count in BALF of LPS group is unknown to us.

LPS can activate neutrophils and macrophages to produce reactive oxygen species (ROS) [27] which lead to the production of inflammatory mediators such as generation of diverse pro-inflammatory Th1 type cytokines including IFN- $\gamma$ [28] as well as inflammatory cytokines and chemokines which recruit more neutrophils to tissues exposed by LPS, and propagate the inflammation process [27-29]. IL-4 also caused substantial reductions in neutrophil content in BALF [30]. Thus, inhibition of iNOS can be helpful in reducing systemic and lung inflammation.

It was shown that TGF- $\beta$ suppress the macrophage response to LPS, in vitro and decreased systemic inflammation [31] and plays an important role in 

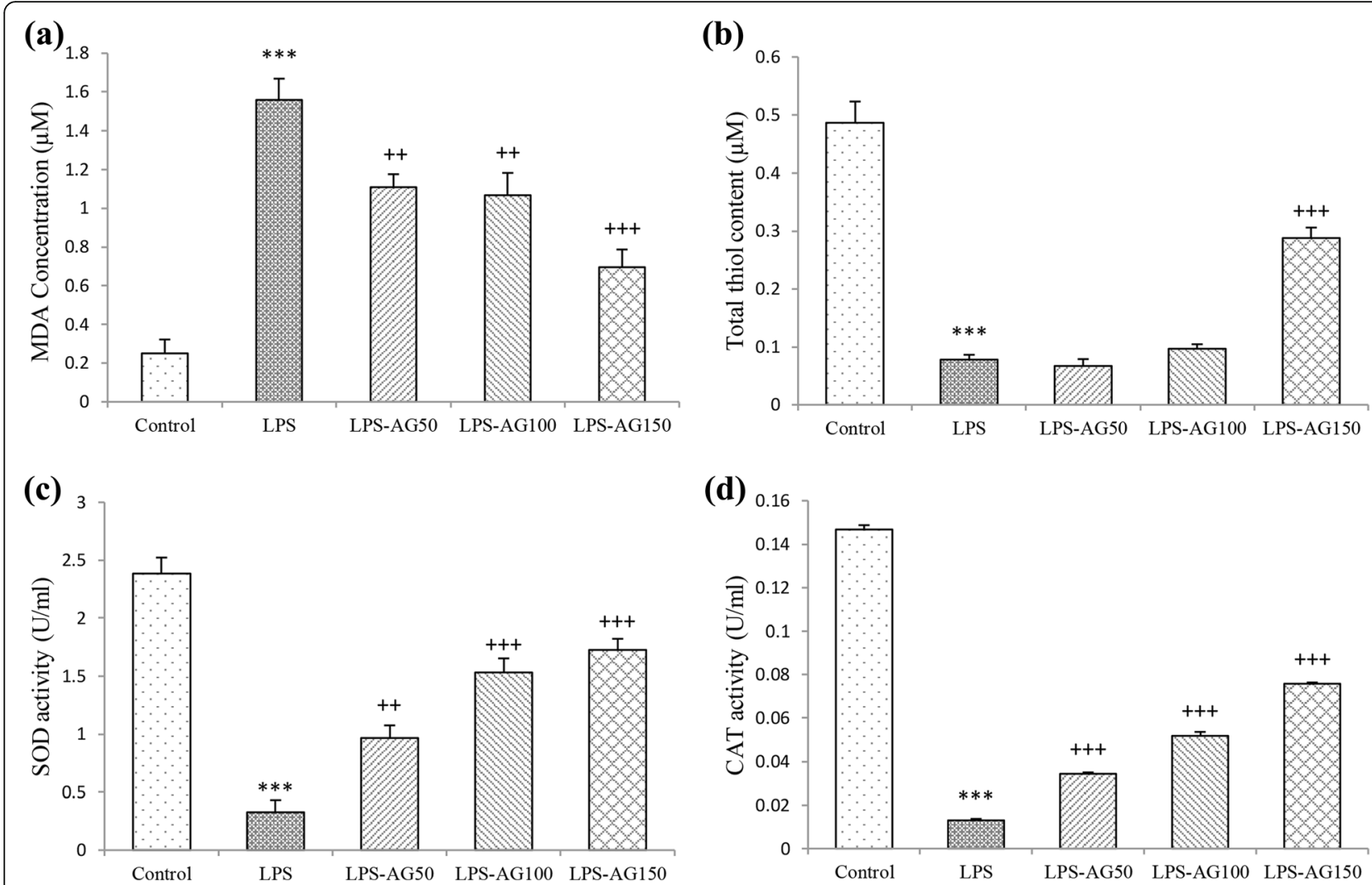

Fig. 5 MDA concentration (a), thiol content (b), SOD (c) and CAT activities (d) in BALF. Data are shown as mean \pm SEM $\left(n=10\right.$ per group). ${ }^{* * * ; P<}$ 0.001 compared to control group, $++; P<0.01$ and $+++; P<0.001$ compared to LPS group. Statistical analysis were performed using one-way analysis of variance (ANOVA) followed by Tukey's multiple comparison test

epithelial changes, sub-epithelial fibrosis, airway smooth muscle remodeling, and microvascular changes [32]. Previous studies also showed increased serum levels of TGF- $\beta$ in LPS-induced inflammation [31], which is in agreement with results of the current study.

Elevated IL-1 $\beta$, IL-4, IL-6 and IFN- $\gamma$ levels in lung tissue, one hour after administration [33] and increased IL-1 $\beta$ mRNA, IL-10 mRNA, and IL-4 protein at one hour after LPS challenge in the lung of mice [34] were reported. Down-regulation IL-10, and up-regulation off TNF- $\alpha$, IL- 6 , IL- 4 and IL- $1 \beta$ production in the BALF [35] as well as a significant up-regulation in the gene expression of TNF- $\alpha$, IL- $1 \beta$, IL- 6 and IL-12, and a down-regulation in the gene expression of IL-4 and IL-10 were observed in LPS-induced acute lung injury in vivo and in vitro [36]. In LPS three-hit model of rat acute lung injury induced by LPS $(1.5 \mathrm{mg} / \mathrm{kg})$ injected into the endotracheal following by i.p. injection of LPS $(3 \mathrm{mg} / \mathrm{kg})$ and then endotracheal administration of LPS $(3 \mathrm{mg} / \mathrm{kg})$ $48 \mathrm{~h}$ later, the expression of TNF- $\alpha$ and IFN- $\gamma$ was first enhanced but declined thereafter. The results of the above mentioned studies were in line with the results of the present study. Therefore, LPS induces Th1 responses (IFN- $\gamma$ ) and inhibits Th2 responses through the TLR4-dependent pathway that triggers the activity of NOS-II [37].

PGE2 could modulate the activity of NOS by the direct effect of TNF $\alpha$ on the release of NO from macrophages or synergic effect of TNF $\alpha$ with IFN- $\gamma$ [38]. In a rat acute lung injury model, intratracheal administration of LPS reduced the content of arachidonic acid in blood neutrophils and increased the level of PGE2 in BALF [25]. The elevated level of PGE2 following administration of LPS may have a protective role in the lungs, but its function may depend on acute or chronic nature of inflammatory response.

LPS three-hits can induce rapid pulmonary fibrosis which the first rapid pulmonary fibrosis stage occurred on days 3-7, whereas from 14 to 21 days was the second stage [39]. Acute infusion of LPS $(5 \mathrm{mg} / \mathrm{kg}$ over $60 \mathrm{~min}$ ) in rabbits caused extensive morphologic lung damage [24]. Chronic LPS exposure can cause neutrophil-dependent emphysematous changes in lung architecture and result in other pulmonary changes such as airway wall thickening, mucus cell metaplasia, irreversible alveolar enlargement, and the chronic 

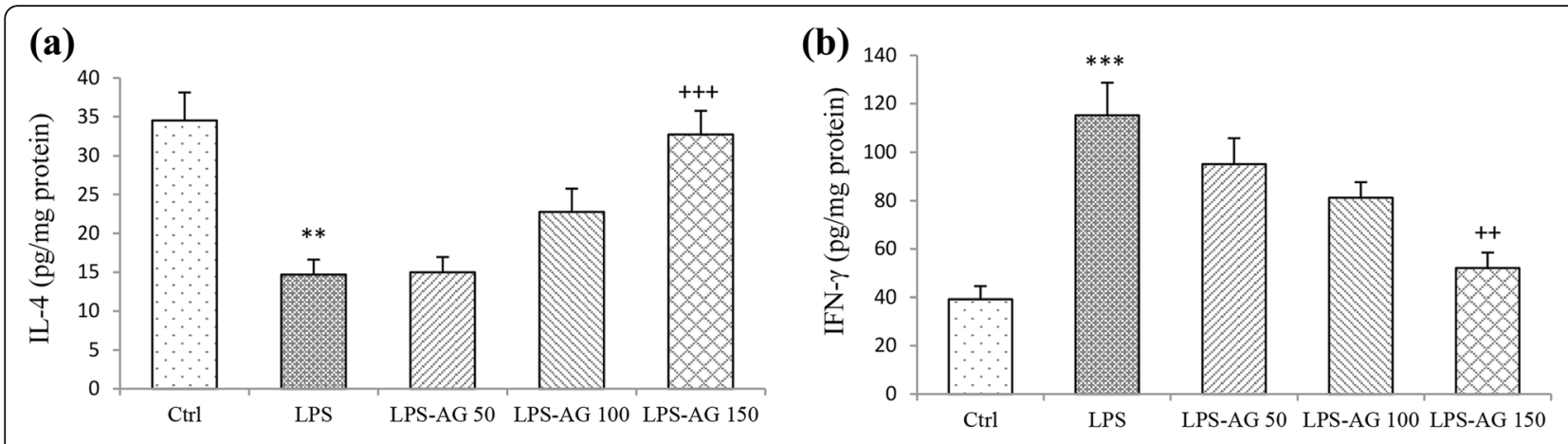

(c)
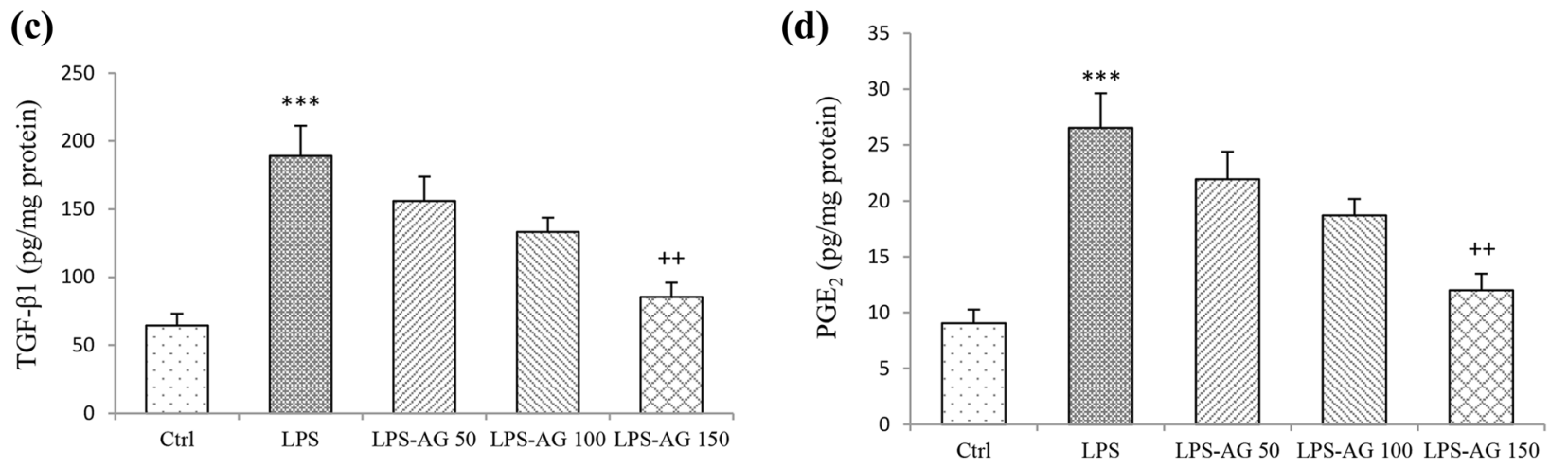

Fig. 6 The levels of IL-4 (a), IFN- $\gamma(\mathbf{b})$, TGF $\beta 1$ (c), and PGE2 (d) in BALF. Data are shown as mean \pm SEM ( $n=10$ per group). **;P $<0.01$ and ***; $P<0.001$ compared to control group, $++; P<0.01$ and $+++; P<0.001$ compared to LPS group. Statistical analysis were performed using one-way analysis of variance (ANOVA) followed by Tukey's multiple comparison test

inflammatory response $[3,10,40]$. Therefore, the inflammatory and pathologic changes were similar with lung pathological changes in chronic inflammatory lung diseases, especially COPD patients, suggesting that this murine model could be applicable to the pathogenesis of COPD condition [3].

Treatment with AG resulted in a decrease in total nitrite concentration and WBC count. AG modified oxidative status by decreasing the levels of MDA and increasing total thiol content as well as SOD and CAT activities both in serum and BALF of LPS-AG groups. Increased IL-4 level and decreased IFN- $\gamma$, TGF- $\beta 1$, PGE2 levels in BALF of AG treated was also observed. The pathological changes in the lung tissues including interstitial inflammation and lymphoid infiltration were also improved due to AG treatments dose-dependently.

The inhibitory effect of AG on iNOS was reported in a dose-dependent manner [41] in various conditions such as in rat model of hemorrhagic shock $[42,43]$ and in LPS-induced increased NO production in the primary culture of rat hepatocytes [15]. In the present study, the similar pattern was observed for the inhibitory effect of AG on nitrite level in the serum and BALF of chronic LPS exposure-induced lung injury. Acute infusion of AG ( $1 \mathrm{mg} / \mathrm{kg}$ one hour after the end of LPS infusion) in rabbits decreased neutrophil count in BALF [24]. However, this effect was not observed in the LPS-induced blood neutrophilia in the present study. This contradiction may be related to the type of inflammation or may be due to the acute and chronic effects of AG. The present findings suggest that AG probably reduces up-regulation of iNOS by decreasing alveolar macrophages. The relationships between COX-2 and iNOS isoforms were previously reported [44]. AG can reduce the production of NO and PGE2 induced by LPS injection and affected the PG metabolism by inhibiting COX-2 expression and its activity [45]. The current findings suggest that iNOS-mediated NO production could result in lung damage and this could lead to up-regulation of COX-2, which increases the production of ROS and toxic prostanoids.

AG is able to scavenge hydroxyl and peroxyl radicals [46] in various conditions including experimental model of diabetes mellitus which it reduced the levels of pulmonary oxidative stress and increased collagen synthesis and deposition in the lung [47] as well as against a single dose of paraquat-induced oxidative stress in the lung of mice [48] which support the results of the current study.

AG also preserved lung function and shifted the Th2 to the Th1 response with a reduction of IL- 4 and IL-13 

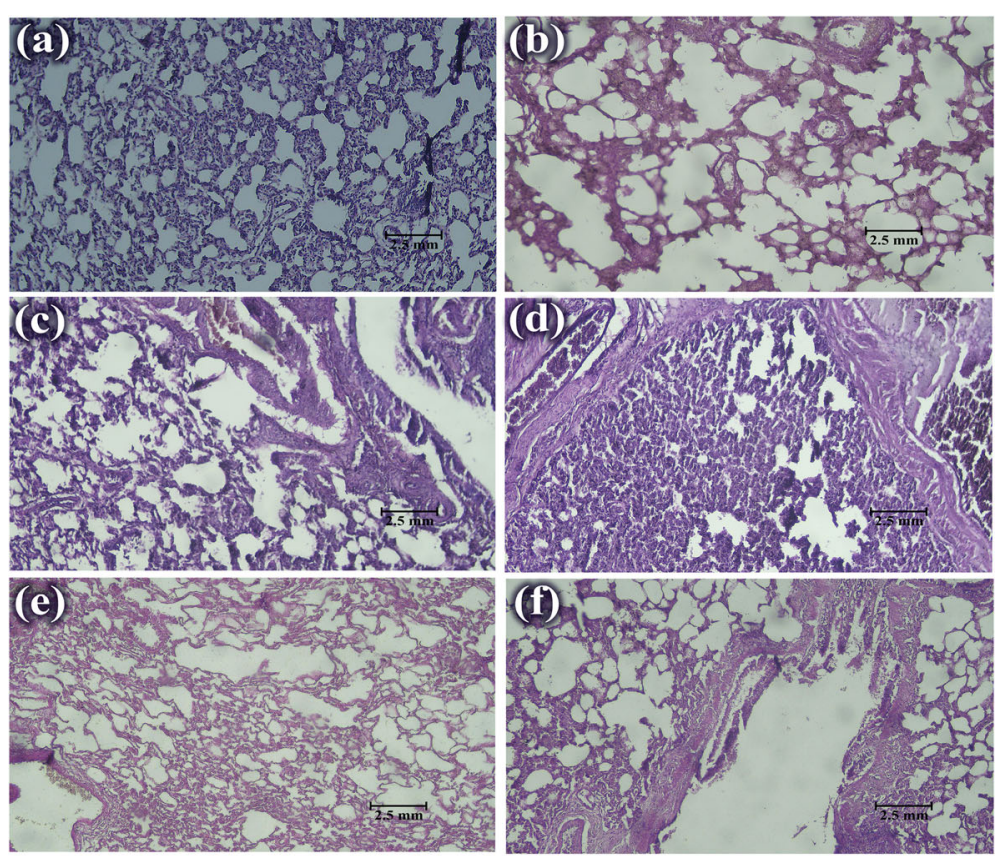

(g)

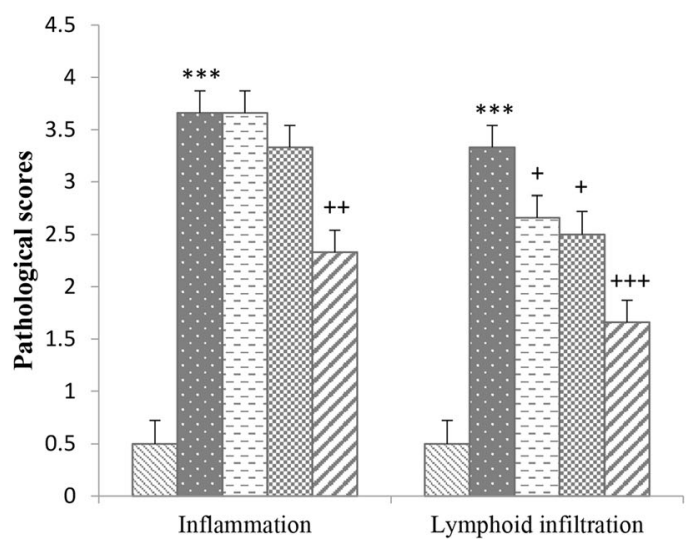

$₫ \mathrm{Ctrl}$

- LPS

口LPS-AG 50

๑LPS-AG 100

$\triangle$ LPS-AG 150

Fig. 7 Photographs of a lung specimen in control lung tissues (a), interstitial inflammation and lymphoid infiltration in LPS (b and c), AG50 (d), AG100 (e) and AG150 (f) groups (magnification for each group; $10 \times 20$; scale bar; $2.5 \mathrm{~mm}$ ). The degree of lung injury was measured using lung pathological score $(\mathbf{g})$. ${ }^{* * *} ; P<0.001$ compared to control group, $+; P<0.05,++; P<0.01$ and $+++; P<0.001$ compared to LPS group. Data are shown as mean $\pm \mathrm{SEM}$. The lung pathological changes were scored as follows: 1) no pathologic changes, 0 ; 2) patchy changes, 1; 3) local changes, 2; 4) scattered changes, 3 and 5) severe changes (in the most parts of the lung), 4. Statistical analysis were performed using one-way analysis of variance (ANOVA) followed by Tukey's multiple comparison test

and increase in IL- $1 \beta$ production in ovalbumin sensitized animals [49] which caused increase IL-4 level unlike LPS-induced inflammation. Reduction of glomerular iNOS and TGF- $\beta 1$ mRNA expression in mice and rats models of glomerulosclerosis and diabetic nephropathy by AG were also reported $[50,51]$ which were in line with the results of lung injury induced by LPS of the present study. The absence of the effect of AG on in vivo expression of TNF $\alpha$ and IL-1 $\beta$ in the lungs of endotoxemic rats was reported [41] but there are reports on the effect of AG in the serum and tissue cytokine levels [41]. However, the effect of AG on BALF level of cytokine and oxidant, anti-oxidant has not been studied extensively.

Histological examinations showed a reduction in kidney, liver, lung, and brain damages for AG [42]. It is suggested that the treatment of rabbits with infusion of AG, attenuated acute lung injury and inflammation following intravenous exposure to LPS [24]. AG also prevented bleomycin-induced lung fibrosis in both rats and mice $[52,53]$ which were in agreement with the present findings in the chronic lung injury by LPS. Due to the role of TGF- $\beta$ in most of the biological processes leading to the airway remodeling, 
reduced BALF level of TGF- $\beta 1$ can lead to improved pathological changes in the lung tissue.

There are no findings about the possible mechanisms of AG in chronic lung injury induced by LPS. Based on the results of this study, potential mechanisms of AG may be via dual inhibition of NO and PGE2, enhanced production of IL-4, as a strong anti-inflammatory cytokine, which in turn decreased inflammatory cytokines, IFN- $\gamma$ and TGF- $\beta 1$, as well as monocyte chemotaxis. The radical scavenging properties of AG may help to explain the modulation of lung and systemic inflammation by this compound.

Although the protective effects of AG on lung disorders was examined in several previous studies as listed above, the unique novelty of the present study is evaluating of the effect of AG on chronic lung injury induced by LPS administration which is an endotoxin-induced lung injury model. However, there are some similarities between chronic endotoxin-induced lung injury model and COPD [3]. In addition, LPS is present as a contaminant in cigarette-smoke [2] the main cause of COPD. Therefore, AG could be also a potential therapeutic candidate for treatment of COPD which should be examined in further studies.

There was no any mortality among studied animals of different groups but body weight changes was not evaluated which should be evaluated in further studies. In fact, both animal and human studies indicated very low toxicity of AG. However, high doses of AG are associated with some adverse effects such as autoimmune symptoms, abnormal liver function, gastrointestinal disturbance, and flu-like symptoms [54, 55]. In the present study, the left lungs were removed and placed into $10 \%$ buffered formalin for lung pathological evaluation and the right lung was washed with normal saline for preparation of BALF samples and the pro-inflammatory mediator levels were measured in BALF according the previous studies $[18,56]$. It is well-known that evaluation of all parameters in a single study is impossible. Therefore, quantify steady state mRNA levels of the proinflammatory molecules and oxidative stress/antioxidative stress related genes were not evaluated in the present study and should be examined in further studies. Similarly, in vitro experiments for the involvement of specific cell type in systemic inflammation and lung injury induced by chronic LPS administration should be also examined in further studies.

\section{Conclusion}

The present study showed that AG modulated immune and inflammatory responses in chronic lung injury by LPS administration. Therefore, AG has a protective role in LPS-induced lung injury caused by inflammation and oxidative stress. The results of the present study suggest that inhibition of iNOS by AG may be effective in the treatment of systemic and lung inflammation by both decreasing the nitrite level and/or possibly the involvement of cytokines.

\section{Abbreviations \\ AG: Aminoguanidine; BALF: Bronchoalveolar lavage fluid; CAT: Catalase; COPD: Chronic obstructive pulmonary disease; COX: Cyclo-oxygenase; \\ DTNB: 5, 5'-dithiobis-(2-nitrobenzoic acid); IL-1: Interleukin-1; IL-4: Interleukin- 4; IL-6: Interleukin-6; IL-8: Interleukin-8; INF-y: Interferon gamma; iNOS: Inducible nitric oxide synthase; LPS: Lipopolysaccharide; MDA: Malondialdehyde; MTT: 3-(4,5-Dimethylthiazol-2-yl)-2,5- diphenyltetrazolium bromide; NO: Nitric oxide; NOS: Nitric oxide synthase; PGE2: Prostaglandin-E2; ROS: Reactive oxygen species; SOD: Superoxide dismutase; TBA: Thiobarbituric acid; TGF- $\beta 1$ : Transforming growth factor- beta-1; TNF-a: Tumor necrosis factor-alpha; WBC: White blood cell}

\section{Acknowledgements}

This study was financially supported by a grant from Research Council of Mashhad University of Medical Sciences.

Funding

Not applicable.

Availability of data and materials

Not applicable.

\section{Authors' contributions}

MHB presented idea, developed the theory and performed the computations and encouraged SS to investigate the effects of Aminoguanidine on systemic and lung inflammation, and supervised the findings of this work. FB and SS carried out the experiments. VRA contributed to the interpretation of the results. SS analyzed the data and wrote the paper. All authors read and approved the final manuscript.

Ethics approval and consent to participate

The study was approved by the ethics committee of Mashhad University of Medical Sciences for Animal Experiments (code 951071).

Consent for publication

Not applicable.

\section{Competing interests}

The authors declare that they have no competing interests.

\section{Publisher's Note}

Springer Nature remains neutral with regard to jurisdictional claims in published maps and institutional affiliations.

\footnotetext{
Author details

${ }^{1}$ Neurogenic Inflammation Research Center, Mashhad University of Medical Sciences, Mashhad 9177948564, Iran. ²Department of Physiology, School of Medicine, Mashhad University of Medical Sciences, Mashhad 9177948564 Iran. ${ }^{3}$ Neuroscience Research Center, Torbat Heydariyeh University of Medical Sciences, Torbat Heydariyeh, Iran. ${ }^{4}$ Department of Physiology, School of Paramedical Sciences, Torbat Heydariyeh University of Medical Sciences, Torbat Heydariyeh, Iran. ${ }^{5}$ Student Research Committee, Department of Pharmacology, Faculty of Medicine, Mashhad University of Medical Sciences, Mashhad, Iran. 'Department of Pathology, School of Medicine, Mashhad University of Medical Sciences, Mashhad, Iran.
} 
Received: 15 December 2018 Accepted: 22 April 2019

Published online: 22 May 2019

\section{References}

1. Blais DR, Vascotto SG, Griffith M, Altosaar I. LBP and CD14 secreted in tears by the lacrimal glands modulate the LPS response of corneal epithelial cells. Invest Ophthalmol Vis Sci. 2005;46:4235-44.

2. Pera T. Inflammation and Remodelling in experimental models of COPD: mechanisms and therapeutic perspectives: university library Groningen][host]; 2011.

3. Vernooy JH, Dentener MA, Van Suylen RJ, Buurman WA, Wouters EF. Longterm intratracheal lipopolysaccharide exposure in mice results in chronic lung inflammation and persistent pathology. Am J Respir Cell Mol Biol. 2002;26:152-9.

4. Weigand MA, Hörner C, Bardenheuer HJ, Bouchon A. The systemic inflammatory response syndrome. Best Pract Res Clin Anaesthesiol. 2004;18: 455-75.

5. Baradaran Rahimi V, Rakhshandeh H, Raucci F, Buono B, Shirazinia R, Samzadeh Kermani A, et al. Anti-inflammatory and anti-oxidant activity of Portulaca oleracea extract on LPS-induced rat lung injury. Molecules. 2019; 24:139.

6. Ye J, Guan M, Lu Y, Zhang D, Li C, Zhou C. Arbutin attenuates LPS-induced lung injury via Sirt1/Nrf2/NF-kBp65 pathway. Pulm Pharmacol Ther. 2019;54: 53-9.

7. Magalhães CB, Casquilho NV, Machado MN, Riva DR, Travassos LH, LealCardoso $\mathrm{JH}$, et al. The anti-inflammatory and anti-oxidative actions of eugenol improve lipopolysaccharide-induced lung injury. Resp Physiol Neurobi. 2019;259:30-6.

8. Gao Z, Liu X, Wang W, Yang Q, Dong Y, Xu N, et al. Characteristic antiinflammatory and antioxidative effects of enzymatic-and acidic-hydrolysed mycelium polysaccharides by Oudemansiella radicata on LPS-induced lung injury. Carbohydr Polym. 2019;204:142-51.

9. Toward TJ, Broadley KJ. Goblet cell hyperplasia, airway function, and leukocyte infiltration after chronic lipopolysaccharide exposure in conscious Guinea pigs: effects of rolipram and dexamethasone. J Pharmacol Exp Ther. 2002;302:814-21.

10. Brass DM, Hollingsworth JW, Cinque M, Li Z, Potts E, Toloza E, et al. Chronic LPS inhalation causes emphysema-like changes in mouse lung that are associated with apoptosis. Am J Respir Cell Mol Biol. 2008;39:584-90.

11. Wright JL, Churg A. Animal models of COPD: barriers, successes, and challenges. Pulm Pharmacol Ther. 2008;21:696-8.

12. Fehrenbach $\mathrm{H}$. Animal models of pulmonary emphysema: a stereologist's perspective. Eur Respir Rev. 2006;15:136-47.

13. Tunçtan B, Altu S. Effects of nitric oxide synthase inhibition in lipopolysaccharide-induced sepsis in mice. Pharmacol Res. 1998;38:405-11.

14. Coleman JW. Nitric oxide in immunity and inflammation. Int Immunopharmacol. 2001;1:1397-406.

15. Zhang G-L, Wang $Y-H$, Teng H-L, Lin Z-B. Effects of aminoguanidine on nitric oxide production induced by inflammatory cytokines and endotoxin in cultured rat hepatocytes. World J Gastroenterol. 2001;7:331.

16. Parlakpinar H, Koc M, Polat A, Vardi N, Ozer M, Turkoz Y, et al. Protective effect of aminoguanidine against nephrotoxicity induced by amikacin in rats. Urol Res. 2004;32:278-82.

17. Evgenov OV, OH ØY, Bremnes KE, Bjertnaes $\sqcup$. Effect of aminoguanidine on lung fluid filtration after endotoxin in awake sheep. Am J Respir Crit Care Med. 2000;162:465-70.

18. Boskabadi J, Mokhtari-Zaer A, Abareshi A, Khazdair MR, Emami B, Mohammadian Roshan N, et al. The effect of captopril on lipopolysaccharide-induced lung inflammation. Exp Lung Res. 2018:1-10.

19. Nematollahi S, Nematbakhsh M, Haghjooyjavanmard S, Khazaei M, Salehi M. Inducible nitric oxide synthase modulates angiogenesis in ischemic hindlimb of rat. Biomed Pap Med Fac Univ Palacky Olomouc Czech Repub. 2009;153:125-9.

20. Shakeri F, Soukhtanloo M, Boskabady MH. The effect of hydro-ethanolic extract of Curcuma longa rhizome and curcumin on total and differential WBC and serum oxidant, antioxidant biomarkers in rat model of asthma. Iran J Basic Med Sci. 2017;20:155.

21. Boskabady MH, Tabatabaee A, Jalali S. Potential effect of the extract of Zataria multiflora and its constituent, carvacrol, on lung pathology, total and differential WBC, IgE and eosinophil peroxidase levels in sensitized Guinea pigs. J Funct Foods. 2014;11:49-61.
22. Reutershan J, Basit A, Galkina EV, Ley K. Sequential recruitment of neutrophils into lung and bronchoalveolar lavage fluid in LPS-induced acute lung injury. Am J Physiol Lung Cell Mol Physiol. 2005;289:L807-L15.

23. Sandstrom T, Bjermer L, Rylander R. Lipopolysaccharide (LPS) inhalation in healthy subjects increases neutrophils, lymphocytes and fibronectin levels in bronchoalveolar lavage fluid. Eur Respir J. 1992;5:992-6.

24. Mikawa K, Nishina K, Tamada M, Takao Y, Maekawa N, Obara H. Aminoguanidine attenuates endotoxin-induced acute lung injury in rabbits. Crit Care Med. 1998;26:905-11.

25. Vancheri C, Mastruzzo C, Sortino MA, Crimi N. The lung as a privileged site for the beneficial actions of PGE2. Trends Immunol. 2004;25:40-6.

26. Wohlford-Lenane CL, Deetz DC, Schwartz DA. Cytokine gene expression after inhalation of corn dust. Am J Physiol Lung Cell Mol Physiol. 1999;276: L736-L43.

27. Li L, Shoji W, Takano H, Nishimura N, Aoki Y, Takahashi R, et al. Increased susceptibility of MER5 (peroxiredoxin III) knockout mice to LPS-induced oxidative stress. Biochem Biophys Res Commun. 2007;355:715-21.

28. Mukherjee S, Chen L-Y, Papadimos TJ, Huang S, Zuraw BL, Pan ZK. Lipopolysaccharide-driven Th2 cytokine production in macrophages is regulated by both MyD88 and TRAM. J Biol Chem. 2009;284:29391-8.

29. Held TK, Weihua X, Yuan L, Kalvakolanu DV, Cross AS. Gamma interferon augments macrophage activation by lipopolysaccharide by two distinct mechanisms, at the signal transduction level and via an autocrine mechanism involving tumor necrosis factor alpha and interleukin-1. Infect Immun. 1999;67:206-12.

30. Mulligan MS, Jones ML, Vaporciyan AA, Howard MC, Ward PA. Protective effects of IL-4 and IL-10 against immune complex-induced lung injury. J Immunol. 1993;151:5666-74.

31. Garcia-Lazaro JF, Thieringer F, Lüth S, Czochra P, Meyer E, Renteria IB, et al. Hepatic over-expression of TGF-beta1 promotes LPS-induced inflammatory cytokine secretion by liver cells and endotoxemic shock. Immunol Lett. 2005;101:217-22.

32. Halwani R, Al-Muhsen S, Al-Jahdali H, Hamid Q. Role of transforming growth factor- $\beta$ in airway remodeling in asthma. Am J Respir Cell Mol Biol. 2011;44: 127-33.

33. Kabir K, Gelinas J-P, Chen M, Chen D, Zhang D, Luo X, et al. Characterization of a murine model of endotoxin-induced acute lung injury. Shock. 2002;17: 300-3.

34. Barsig J, Küsters S, Vogt K, Volk HD, Tiegs G, Wendel A. Lipopolysaccharideinduced interleukin-10 in mice: role of endogenous tumor necrosis factor-a. Eur J Immunol. 1995;25:2888-93.

35. Fu K, Piao T, Wang M, Zhang J, Jiang J, Wang X, et al. Protective effect of catalpol on lipopolysaccharide-induced acute lung injury in mice. Int Immunopharmacol. 2014;23:400-6.

36. Yeh C-C, Kao S-J, Lin C-C, Wang S-D, Liu C-J, Kao S-T. The immunomodulation of endotoxin-induced acute lung injury by hesperidin in vivo and in vitro. Life Sci. 2007;80:1821-31.

37. Rodríguez D, Keller AC, Faquim-Mauro EL, de Macedo MS, Cunha FQ, Lefort J, et al. Bacterial lipopolysaccharide signaling through toll-like receptor 4 suppresses asthma-like responses via nitric oxide synthase 2 activity. J Immunol. 2003;171:1001-8.

38. Milano S, Arcoleo F, Dieli M, D'Agostino R, D'Agostino P, De Nucci G, et al. Prostaglandin E2 regulates inducible nitric oxide synthase in the murine macrophage cell line J774. Prostaglandins. 1995;49:105-15.

39. Li H, Du S, Yang L, Chen Y, Huang W, Zhang R, et al. Rapid pulmonary fibrosis induced by acute lung injury via a lipopolysaccharide three-hit regimen. Innate Immunity 2009;15:143-154. PubMed PMID: 19474208.

40. Stolk J, Rudolphus A, Davies P, Osinga D, Dijkman JH, Agarwal L, et al. Induction of emphysema and bronchial mucus cell hyperplasia by intratracheal instillation of lipopolysaccharide in the hamster. J Pathol. 1992;167:349-56.

41. Joshi PC, Grogan JB, Thomae KR. Effect of aminoguanidine on in vivo expression of cytokines and inducible nitric oxide synthase in the lungs of endotoxemic rats. Res Commun Mol Pathol Pharmacol. 1996;91:339-46.

42. Md S, Moochhala SM, Yang KLS, Lu J, Anuar F, Mok P, et al. The role of selective nitric oxide synthase inhibitor on nitric oxide and PGE2 levels in refractory hemorrhagic-shocked rats. J Surg Res. 2005;123:206-14.

43. Hua TC, Moochhala SM. Influence of L-arginine, aminoguanidine, and NGnitro-L-arginine methyl ester (L-name) on the survival rate in a rat model of hemorrhagic shock. Shock (Augusta, Ga). 1999;11:51-7.

44. Posadas I, Terencio MC, Guillén I, Ferrándiz ML, Coloma J, Payá M, et al. Coregulation between cyclo-oxygenase-2 and inducible nitric oxide synthase 
expression in the time-course of murine inflammation. Naunyn Schmiedeberg's Arch Pharmacol. 2000;361:98-106.

45. Ribeiro M, Cella M, Farina M, Franchi A. Effects of aminoguanidine and cyclooxygenase inhibitors on nitric oxide and prostaglandin production, and nitric oxide synthase and cyclooxygenase expression induced by lipopolysaccharide in the estrogenized rat uterus.

Neuroimmunomodulation. 2004;11:191-8.

46. Courderot-Masuyer C, Dalloz F, Maupoil V, Rochette L. Antioxidant properties of aminoguanidine. Fundam Clin Pharmacol. 1999;13:535-40.

47. Naso FCD, Forgiarini Junior LA, Forgiarini LF, Porawski M, Dias AS, Marroni NAP. Aminoguanidine reduces oxidative stress and structural lung changes in experimental diabetes mellitus. J Bras Pneumol. 2010;36:485-9.

48. Mustafa A, Gado AM, Al-Shabanah OA, Al-Bekairi AM. Protective effect of aminoguanidine against paraquat-induced oxidative stress in the lung of mice. Comp Biochem Physiol C Toxicol Pharmacol. 2002;132:391-7.

49. Nesi RT, Barroso MV, Vd SM, de Arantes AC, Martins MA, Ld BG, et al. Pharmacological modulation of reactive oxygen species (ROS) improves the airway hyperresponsiveness by shifting the Th1 response in allergic inflammation induced by ovalbumin. Free Radic Res. 2017;51:708-22.

50. Kelly DJ, Gilbert RE, Cox AJ, Soulis T, Jerums G, Cooper ME. Aminoguanidine ameliorates overexpression of prosclerotic growth factors and collagen deposition in experimental diabetic nephropathy. J Am Soc Nephrol. 2001; 12:2098-107.

51. Yang $C$, Yu C, Ko Y, Huang C. Aminoguanidine reduces glomerular inducible nitric oxide synthase (iNOS) and transforming growth factor-beta 1 (TGF- $\beta 1$ ) mRNA expression and diminishes glomerulosclerosis in NZB/W F1 mice. Clin Exp Immunol. 1998;113:258.

52. Yildirim Z, Turkoz Y, Kotuk M, Armutcu F, Gurel A, Iraz M, et al. Effects of aminoguanidine and antioxidant erdosteine on bleomycin-induced lung fibrosis in rats. Nitric Oxide. 2004;11:156-65.

53. Giri S, Biring I, Nguyen T, Wang Q, Hyde D. Abrogation of bleomycininduced lung fibrosis by nitric oxide synthase inhibitor, aminoguanidine in mice. Nitric Oxide. 2002;7:109-18.

54. Beheshti F, Hosseini M, Taheri Sarvtin M, Kamali A, Anaeigoudari A. Protective effect of aminoguanidine against lipopolysaccharide-induced hepatotoxicity and liver dysfunction in rat. Drug and Chemical Toxicology. 2019 2019/01/29:1-7.

55. Hu Y, Wang B, Yang J, Liu T, Sun J, Wang X. Synthesis and biological evaluation of 3-arylcoumarin derivatives as potential anti-diabetic agents. Journal of enzyme inhibition and medicinal chemistry. 2019;34:15-30.

56. Boskabady MH, Mahtaj LG. Lung inflammation changes and oxidative stress induced by cigarette smoke exposure in Guinea pigs affected by Zataria multiflora and its constituent, carvacrol. BMC Complement Altern Med. 2015;15:39.

Ready to submit your research? Choose BMC and benefit from:

- fast, convenient online submission

- thorough peer review by experienced researchers in your field

- rapid publication on acceptance

- support for research data, including large and complex data types

- gold Open Access which fosters wider collaboration and increased citations

- maximum visibility for your research: over $100 \mathrm{M}$ website views per year

At BMC, research is always in progress.

Learn more biomedcentral.com/submissions 